\title{
THE DIAGNOSIS OF VIRUS PNEUMONIA IN INFANTS AND CHILDREN
}

\author{
BY \\ DUNCAN MACAULAY \\ From the Children's Hospital, Derby \\ (Received for Publication May 5, 1951)
}

\begin{abstract}
' The diagnosis of primary atypical pneumonia at the present time is in reality a process of excluding the known specific diseases which may present the same clinical syndrome.' This comment of Dingle's made in 1947 is presumably still true. In infants and children suffering from pneumonia sputum is rarely obtainable, and as Rabe (1948) stated 'the mere presence of a potential pathogen in the rhino-pharyngeal cultures of patients with a respiratory infection does not necessarily mean that the organism is the cause of the disease'. Any attempt at aetiological diagnosis in this age group thus depends on the evaluation of clinical data and the application of such tests as have been reported to be of value in the diagnosis of virus pneumonia. The present report is concerned with an attempt to discover the variations of certain clinical findings in cases of lobar pneumonia in children and with an investigation of two techniques which have been claimed to be of diagnostic value.
\end{abstract}

\section{Atypical Features in Lobar Pneumonia}

So-called primary atypical pneumonia differs clinically from primary bacterial pneumonias in four respects: gradual onset (Reimann, 1947), discrepancy between clinical and radiographic findings, absence of leucocytosis, and failure to respond rapidly to sulphonamides or penicillin.

Israel, Mitterling, and Flippin (1948) refer to the characteristic marked leucocytosis and the dramatic response to sulphonamides or penicillin as 'the two criteria that formerly seemed most valuable in the differentiation of bacterial and viroid pneumonias'. In order to assess the validity of these criteria it is necessary to know the range of these findings in typical cases of pneumonia. The data presented here concern cases of lobar pneumonia in infants and children.
Material. All the cases of lobar pneumonia admitted to the medical wards of the Royal Edinburgh Hospital for Sick Children from April, 1947 , to March, 1949, inclusive have been studied. The information required has been extracted from the case reports; 267 cases are included. In these the diagnosis was established at necropsy in four instances, by radiography in 247 , and by clear-cut and characteristic clinical signs in 16. All cases of pneumonia-bronchopneumonia, terminal pneumonia, and other atypical forms of pulmonary infiltration-except those which seemed on the basis of the available information to be true lobar pneumonia have been excluded from the study. The age distribution of the cases was very similar to that reported previously from this hospital (McNeil, Macgregor and Alexander, 1929; McNeil, 1939).

Results. The results are discussed under the headings type of onset, comparison of clinical and radiological findings, leucocyte response, and response to chemotherapy.

TYPE OF ONSET. In four instances the recorded information is not sufficiently detailed to justify their inclusion. Of the remaining 263 cases two main subdivisions could be established; 175 of these patients were cases of acute onset who had been ill for an average period of only three days before admission. In the other 88 cases the duration of the illness before admission to hospital was considerably longer; the average was 18 days. These two groups will be considered separately.

Cases of Short Duration. In 124 instances the child was said to have been quite well before the onset of the acute symptoms. In the remaining 51 cases there was a short period of ill-health before the onset of the fever. Twenty-seven of these were reported to have had an acute upper respiratory infection for a few days; in the other 24 the 
prodromal illness was characterized by malaise and anorexia without any localizing symptoms. The onset of pneumonia was generally heralded by the appearance of fever, cough, and some respiratory upset. Rigors were uncommon, being reported in only six cases. Rather unexpectedly convulsions were even rarer; they were recorded in only three infants under the age of 2 years.

Cases of Long Duration. These fall into four groups. (1) In 26 cases an acute respiratory illness (variously labelled pneumonia, congestion of the lungs, influenza, etc.) was treated at home with a sulphonamide preparation and admission to hospital sought because of unsatisfactory response or relapse on the discontinuance of treatment. (2) In 27 cases the illness was of low grade and some persistence. The characteristic story was of irregular fever with cough and general malaise lasting for a period of a week or longer, without any marked deterioration and without any apparent tendency to improvement. (3) A further 22 cases had progressive illnesses starting usually with a cold and developing cough, fever, disturbed breathing, chest pain, and other symptoms in deliberate succession but without any clear-cut acute episodes. (4) The final group of 13 cases included a variety of symptom complexes. In most of them respiratory symptoms were not prominent and the illnesses were not suspected to be pneumonia until after admission to hospital. They include children referred with joint pains, persistent vomiting, diarrhoea, and abdominal pain.

If the cases treated at home are excluded (on the grounds that the information about the original onset was usually rather inexact) there are left 237 cases for which detailed histories of the onset are available. Of these $175(74 \%)$ had an acute onset and 62 a subacute onset. This is in accordance with previous reports. McDermott (1946) states that in about three-quarters of cases of lobar pneumonia the onset is sudden. In Heffron's (1939) series of 949 cases the onset was sudden in $70 \%$.

Thus in these 237 cases the disease began abruptly and without warning in $124(53 \%)$. Forty-nine $(21 \%)$ started with symptoms of an acute upper respiratory infection, and in these the onset of the pneumonia was sudden in 27 and insidious in 22 . In $51(21 \%)$ a period of indefinite malaise preceded the pneumonia, and of these 24 had an acute onset of symptoms of pneumonia, while in 27 the onset was insidious. In the remaining 13 cases $(6 \%)$ the onset was bizarre and unusual.

Comparison of Clinical and Radiological Findings. Table 1 summarizes the information obtained from a comparison of the recorded clinical signs and scrutiny of the radiographs. The term 'signs of consolidation' indicates that at some period of the child's stay in hospital signs were detected in the chest which could be interpreted as evidence of pulmonary infiltration. In many cases these signs were by themselves inconclusive, for example, merely diminution of air-entry at one area, but where they were confirmed by radiography they have been accepted as clinical evidence of consolidation.

It is clear from these figures that a discrepancy between physical signs and $x$-ray findings in children cannot be used as a diagnostic criterion as between lobar and atypical pneumonia.

LEUCOCYTE RESPONSE. Table 2 shows the distribution of the leucocyte counts in the cases of acute and subacute onset. Only counts performed within the first three days of admission have been included in this table. These figures indicate that over $10 \%$ of these children had white cell counts of less than 10,000 cells per c.mm.

ReSPONSE To Chemotherapy. In the two years covered by this survey the only powerful drugs generally available for the treatment of pneumonia were sulphonamide preparations and penicillin. These were given to 165 of the cases of acute onset and to 58 of those with subacute onset $(85 \%$ of the total number). The response of these cases has been judged by the rate of decline of fever after the start of therapy. In each case a note was made of the

TABLE 1

Summary of Radiological Evidence

\begin{tabular}{c|c|c|c|c|c}
\hline $\begin{array}{c}\text { Age Group } \\
\text { (years) }\end{array}$ & Total & $\begin{array}{c}\text { No. of } \\
\text { Radio- } \\
\text { graphs }\end{array}$ & $\begin{array}{c}\text { Radiologically Positive } \\
\text { with Clinical Signs of } \\
\text { Consolidation }\end{array}$ & $\begin{array}{c}\text { Radiologically Negative } \\
\text { with Clinical Signs of } \\
\text { Consolidation }\end{array}$ & $\begin{array}{c}\text { Radiologically Positive } \\
\text { with No Clinical Signs } \\
\text { of Consolidation }\end{array}$ \\
\hline $0-2$ & 87 & 84 & 53 & 7 & 24 \\
\hline $2-5$ & 80 & 80 & 65 & 4 & 11 \\
\hline $5-12$ & 100 & 99 & 90 & 16 & 4 \\
\hline Total & 267 & 263 & 208 & & $39(15 \%)$ \\
\hline
\end{tabular}


TABLE 2

Distribution of Leucocyte Counts in Cases of Acute and Subacute Onset

\begin{tabular}{cc|c|c|c|c|c}
\hline & & No. of Counts & Below 10,000 & $10,000-15,000$ & $15,000-20,000$ & Over 20,000 \\
\cline { 3 - 6 } Acute onset &. & 164 & 12 & 39 & 44 & 69 \\
\hline Subacute onset &. & 84 & 17 & 17 & 20 & 30 \\
\hline Total $\quad$. &. & 248 & $29(11 \cdot 7 \%)$ & $56(22 \cdot 6 \%)$ & $64(25 \cdot 8 \%)$ & $99(40 \%)$ \\
\hline
\end{tabular}

day on which the temperature returned permanently to normal following the inception of chemotherapy. The results are shown in Table 3. It will be noticed that, while over three-quarters of the patients became afebrile within 48 hours of the start of specific therapy, in about $15 \%$ the response was appreciably slower. In fact two distinct types of response could be observed. One was a dramatic fall of temperature generally within 48 hours of starting treatment; the other was a more gradual fall by lysis which in some cases took as long as a week before the temperature became permanently normal. This difference has been commented on before. McDermott (1946) notes that in $85 \%$ of his cases treated with penicillin the fever subsided by crisis and in the rest more gradually. Kinsman, Daniels, Cohen, McCracken, D'Alonzo, Martin, and Kirby (1945) reported that of cases treated with sulphadiazine about $10 \%$ responded considerably more slowly than the average. These figures are in substantial agreement with those observed in the present series.

It is apparent then that 10 to $15 \%$ of cases of lobar pneumonia treated with sulphonamides or penicillin exhibit a retarded response to these drugs and that caution is required in any individual case in deciding that this delay indicates that the pneumonia is in any other way 'atypical.'

Summary. In 267 cases of apparently true lobar pneumonia in infants and children the range of variation of four features has been determined. These were the type of onset, the leucocyte response, correlation of clinical and radiographic findings, and the response to chemotherapy. In each of these respects a small but not negligible number of cases showed unusual features and it is contended that the term 'atypical' as applied to the pneumonias of childhood is merely descriptive and cannot be given any aetiological significance.

\section{Cold Agglutinins and Virus Particles in Children}

This section concerns an investigation on an unselected group of infants and children suffering from acute respiratory disorders which was undertaken in an attempt to evaluate two techniques which have been claimed to be of diagnostic value in these conditions.

Material. The cases investigated were those infants and children admitted to the Children's Hospital and the City Hospital, Derby, during a three-month period in 1950, who were suffering from acute bronchitis and pneumonia. It was not possible to examine every such admission for a number of reasons (such as rapid death, early discharge from hospital, and occasionally because of technical difficulties), but the cases were quite unselected and were a representative group of acute bronchopulmonary infections in patients ranging from 3 weeks to 13 years of age. A number of children suffering from other disorders in the

TABLE 3

Analysis of Effect of Antibiotics on Pyrexia in Days

\begin{tabular}{|c|c|c|c|c|c|c|}
\hline Drug Used & $\begin{array}{l}\text { Total } \\
\text { Treated }\end{array}$ & $\begin{array}{c}\text { Afebrile } \\
\text { Throughout }\end{array}$ & $\begin{array}{l}{ }^{* T} \text { T.N. in } \\
24 \text { Hours }\end{array}$ & $\begin{array}{l}\text { T.N. by End } \\
\text { of 2nd Day }\end{array}$ & $\begin{array}{l}\text { T.N. by End } \\
\text { of 3rd Day }\end{array}$ & $\begin{array}{c}\text { Febrile over } \\
3 \text { Days }\end{array}$ \\
\hline Sulphonamide & 124 & 15 & 42 & 93 & 102 & 7 \\
\hline Penicillin & 41 & 6 & 19 & 29 & 30 & 5 \\
\hline $\begin{array}{l}\text { Sulphonamide } \\
\text { penicillin }\end{array}$ & 58 & 5 & 13 & 20 & 36 & 17 \\
\hline Total & 223 & 26 & $74(37 \cdot 6 \%)$ & $152(77 \cdot 2 \%)$ & $168(85 \cdot 3 \%)$ & $29(14 \cdot 7 \%)$ \\
\hline
\end{tabular}

* T.N. = permanent abatement of fever. 
same wards at the same time were similarly examined.

Methods. Besides the usual clinical and pathological examinations cold agglutinin tests were performed on the serum, and pharyngeal swabs were examined for intracellular inclusion bodies. The cold agglutinin tests were performed whenever possible in the second week of the illness (the average period from the onset of the respiratory disease to the performance of the test was $11 \frac{1}{2}$ days) and thereafter as indicated. The technique used was that of Young (1946). Pharyngeal smears were made as early in the course of the disease as possible bronchitis and 48 from a variety of other conditions. Fig. 2 shows the maximum titres obtained in the various groups. Of the 49 cases of pneumonia, 34 were typical acute lobar pneumonia, 13 were diagnosed as primary bronchopneumonia, and the remaining two were cases of lobar pneumonia with delayed resolution. The 'miscellaneous respiratory disease' group included cases of upper respiratory infection (tonsillitis, pharyngitis, otitis media), pulmonary tuberculosis, post-operative pulmonary collapse, fibrocystic disease of the pancreas, bronchiectasis, etc. The 'other conditions' group comprised cases of infective hepatitis, glandular

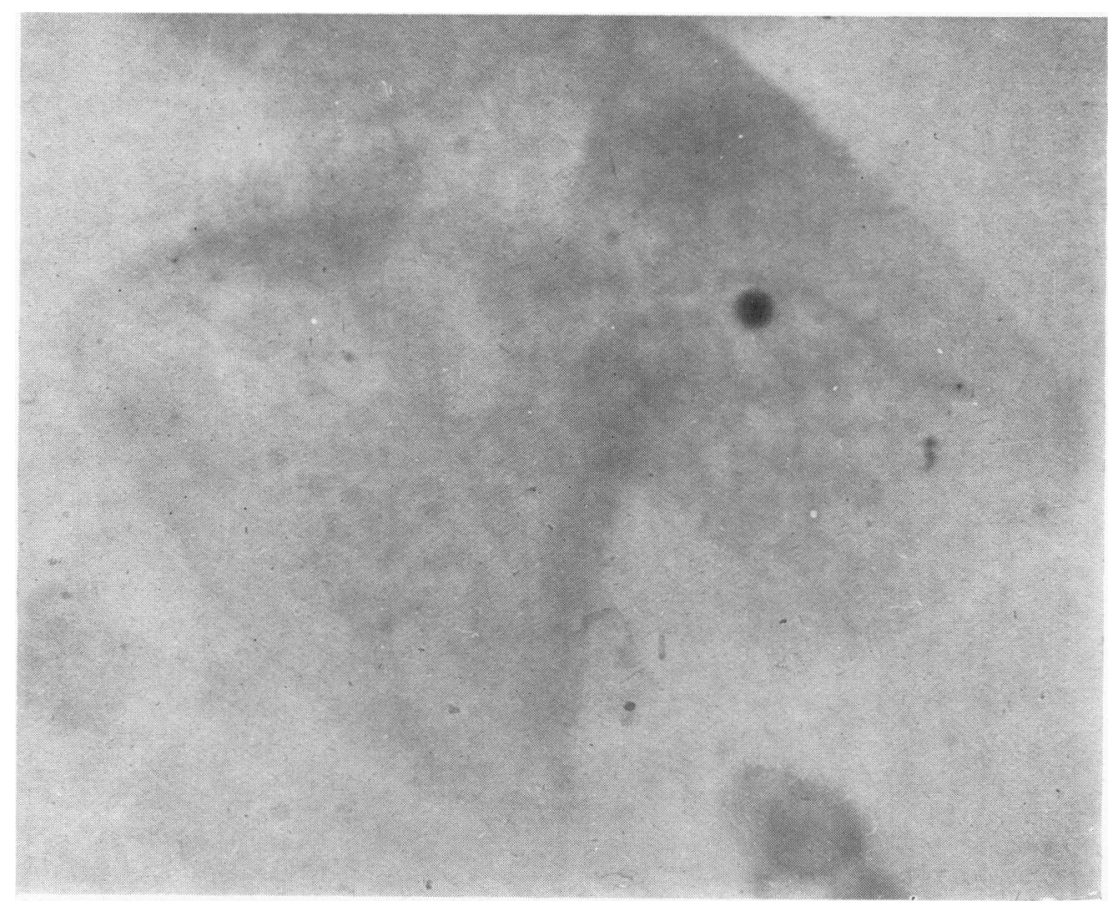

FIG. 1.-Typical particle after Mann's stain.

and were occasionally repeated. The stain employed was Mann's stain (G. T. Gurr). With this stain the particles are easily detected, showing up as bright red, refractile, regular bodies within the cytoplasm of the epithelial cells, generally close to the cell nucleus. Fig. 1 shows a typical body from one of the children in this series.

Results. The results are discussed first as regards the test, and secondly as relating to the inclusion bodies.

Cold Agglutinin Tests. One hundred and sixty-nine tests were performed on 114 patients, of whom 66 were suffering from acute pneumonia or fever, chorea, rheumatic heart disease, epilepsy, chronic skin sepsis, etc.

Young (1946) regards a single titre of $1: 128$ as being of significance in the diagnosis of virus pneumonia, or a titre of $1: 32$ if there is evidence of the appearance of the agglutinins with the infection or their disappearance after it. Using this criterion significant titres were encountered in 26 cases in all. Table 4 shows the number of such titres in the various groups.

In the pneumonia group 12 of the patients with significant titres were suffering from acute lobar pneumonia, one from lobar pneumonia with delayed 
resolution, and four from bronchopneumonia. None of these was regarded, clinically, as being a case of virus pneumonia.

Of the children in the 'miscellaneous respiratory' group showing high or rising titres, one was a case of fibrocystic disease of the pancreas with the chronic staphylococcal bronchopneumonia commonly encountered in that disease, two were suffering from

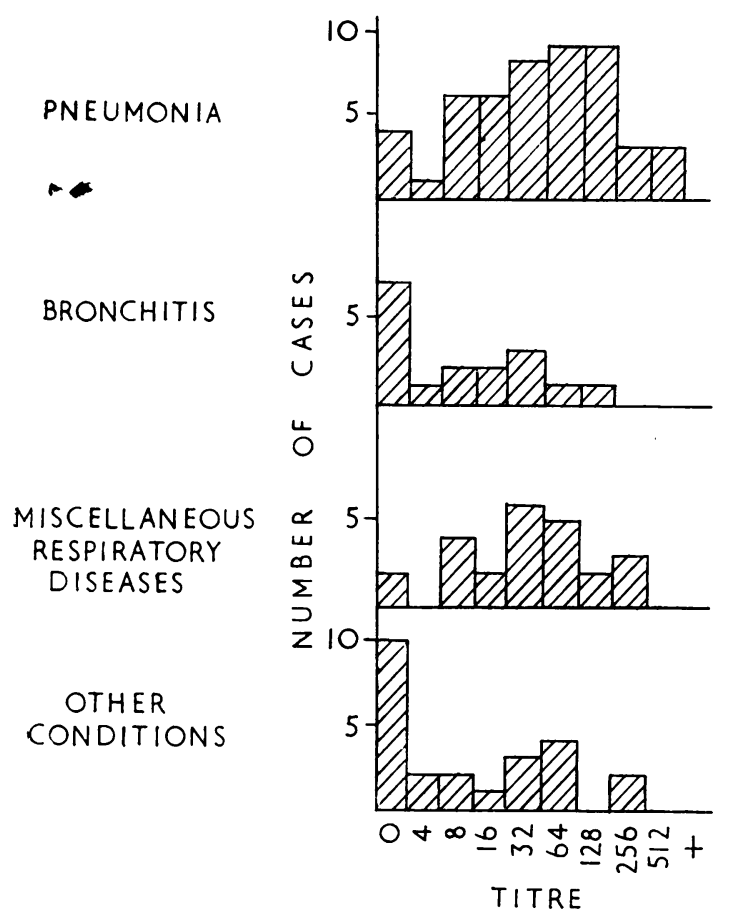

FIG. 2.-Maximum titres obtained in various groups.

primary tuberculous infection of the lungs, one had mas;ive collapse of the left lower lobe following lapaictomy, one was a case of hepatic cirrhosis in whom an unsuspected pulmonary infiltration was

TABLE 4

Analysis of Significant Titres in Various Groups

\begin{tabular}{|c|c|c|c|c|}
\hline \multicolumn{3}{|c|}{ Disease } & Total & $\begin{array}{c}\text { Significant } \\
\text { Titres }\end{array}$ \\
\hline Pneumonia & . & . & 48 & $17(34 \cdot 7 \%)$ \\
\hline Bronchitis .. & $\cdots$ & . & 17 & $1(6 \%)$ \\
\hline Miscellaneous res & pirat & diseases & 24 & $6(25 \%)$ \\
\hline Other conditions & $\cdots$ & $\cdots$ & 24 & $2(8 \cdot 5 \%)$ \\
\hline Total & . & . & 114 & $26(23 \cdot 7 \%)$ \\
\hline
\end{tabular}

discovered on radiography of the chest, and the final case was a child who was admitted with acute otitis media two weeks after an acute cararrhal infection of the lungs. The significant titres in the final group were encountered in a child with Banti's syndrome and in a child with multiple superficial injuries after a road accident. In neither of these was there any evidence of pulmonary damage.

Altogether there were 60 children who were proved to have some involvement of the lung parenchyma-acute pneumonia, unresolved pneumonia, pulmonary tuberculosis, post-operative collapse, radiographic opacities not suspected clinically-and 54 in whom there was no evidence of such a lesion. In the former group 22 cases, or $36.7 \%$, had cold agglutinin titres which were significant according to Young's criteria, whereas

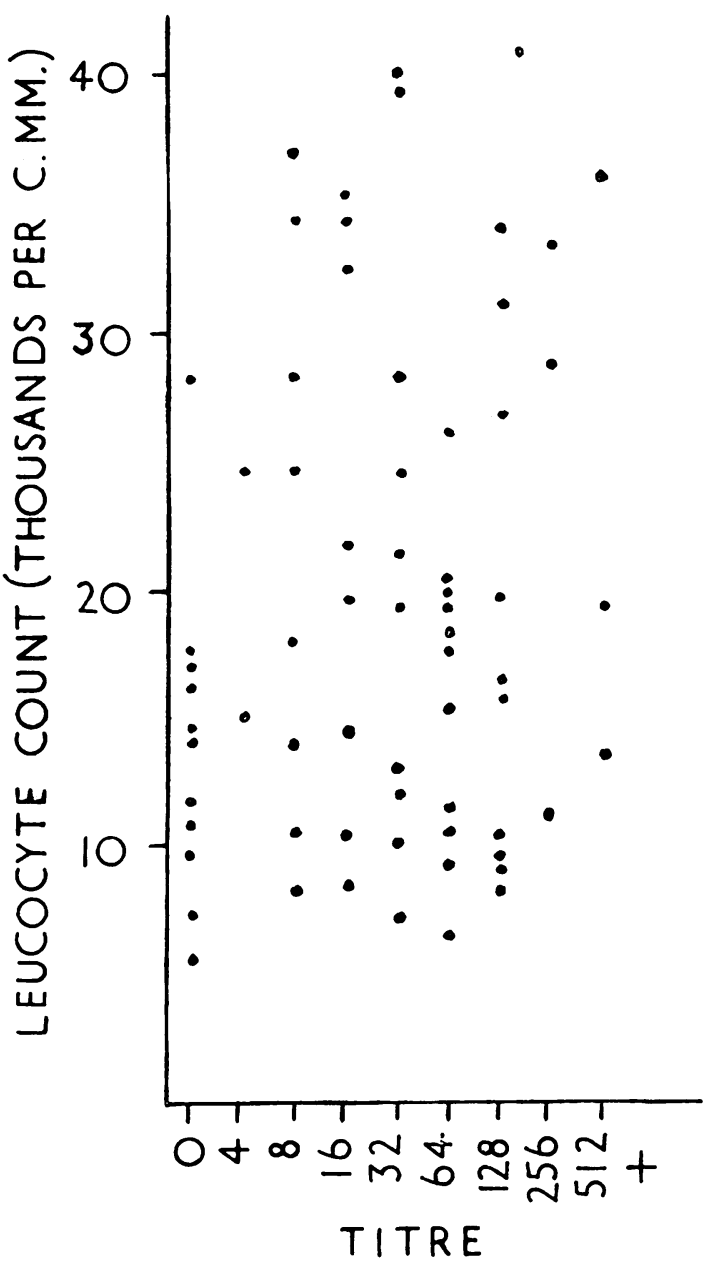

FIG. 3.-Correlation of titres of cold agglutinins with leucocyte response. 
in the latter group only four produced such titres, an incidence of $7 \cdot 4 \%$.

An attempt was made to correlate the titres of cold agglutinins with the leucocyte response in the cases of acute respiratory infection. Fig. 3 shows the result of this investigation. The highest titre attained in each case is shown. There is no apparent relation between the two findings, the leucocyte counts ranging over a wide area at each level of titre.

These children were treated with a number of chemotherapeutic agents-sulphonamides, penicillin, streptomycin, aureomycin, and chloramphenicolsingly and in a variety of combinations. Because of this multiplicity of forms of treatment and the small numbers involved, no precise estimate of the response to chemotherapy of the cases with high and low titres could be formed. However, an attempt was made to detect differences in their behaviour by taking as the index of response permanent abatement of fever within three days of the start of treatment. The cases receiving chloramphenicol or aureomycin have been omitted because of the reported actions of these substances on virus pneumonias. The results in the remaining cases of acute bronchopulmonary infection, i.e. those treated with sulphonamide, penicillin and/or streptomycin, are given in Table 5. The difference in the two groups is not significant.

INCLUSION BoDIES. The frequency with which these bodies were recovered in the whole series is shown in Table 6.

As with cold agglutinins an attempt was made to correlate the presence of pharyngeal inclusions with leucocyte counts and the response to chemotherapy. Since the numbers of positive and negative cases are so unequal no definite conclusions could be drawn, but there was no indication of any direct relationship. The average white cell count in the positive cases was 20,700 cells per c.mm., and in the negative cases 18,800 per c.mm. In both groups approximately $65 \%$ of the children became afebrile within 72 hours of the start of treatment.

The status of the cold agglutinin test is obscure. Young (1946) examined 1,762 sera from patients with a large variety of diseases and concluded that the test was of definite value in the diagnosis of primary atypical pneumonia. He found significant

TABLE 5

Results of Acute Bronchopulmonary Cases Treated WITH ANTIBIOTICS

\begin{tabular}{lr|c|c}
\hline \multicolumn{2}{l|}{ Temperatures Normal } & Significant Titres & Others \\
\hline In 72 hours &. & $11(65 \%)$ & $26(70 \%)$ \\
\hline Over 72 hours &. & $6(35 \%)$ & $11(30 \%)$ \\
\hline
\end{tabular}

TABLE 6

Frequency of Recovery OF INCLUSION Bodies

\begin{tabular}{cc|cc|c}
\hline Disease & $\begin{array}{c}\text { Inclusions } \\
\text { Present }\end{array}$ & $\begin{array}{c}\text { No } \\
\text { Inclusions }\end{array}$ & Total \\
\hline Pneumonia $\ldots$ & $36(88 \%)$ & 5 & 41 \\
\hline Bronchitis $\ldots$ & $13(72 \%)$ & 5 & 18 \\
\hline
\end{tabular}

\begin{tabular}{ll|l|l|c}
\hline $\begin{array}{l}\text { Miscellaneous } \\
\text { respiratory } \\
\text { diseases }\end{array}$ & $\cdots$ & $8(67 \%)$ & 4 & 12 \\
\hline $\begin{array}{l}\text { Other } \\
\text { conditions }\end{array}$ & $\cdots$ & $8(53 \%)$ & 7 & 15 \\
\hline Total & $\cdots$ & $65(76 \%)$ & 21 & 86 \\
\hline
\end{tabular}

titres, apart from that disease, only in rubella, infectious mononucleosis, and certain disorders associated with splenomegaly. On the other hand Savonen (1950), basing his conclusions on the examination of 6,971 specimens (the test was performed on every specimen of serum sent for Wassermann examination), stated that 'cold agglutination primarily is brought about by an injury to the lung,' and he could detect no relation between the clinical type of the lung lesion and the titres attained. The present small series, which differs from Savonen's in that the tests were performed at the optimum period and were repeated when indicated, seems to support this conclusion. No relation between the titres of cold agglutinins and the type of pulmonary lesion, its extent, its duration, the leucocyte count, or the response to chemotherapy, could be established, and the primary determining cause would appear to have been involvement of the lung substance in a pathological process. When this occurred high or rising titres of cold agglutinins were encountered five times as often as in its absence.

Adams (1948); Adams, Green. Evans, and Beach (1942); Adams, Pennoyer, and Whiting (1946) have expressed the opinion that the discovery of inclusion bodies in the pharyngeal epithelium is of value in the diagnosis of virus pneumonia. Gedgoud (1943) found these bodies in 35 of 52 persons suffering from a number of different diseases and also in healthy persons. He stated that on his findings "doubt is cast on the significance of cytoplasmic inclusion bodies as an aid to the diagnosis of the syndrome' (virus pneumonia). Broadhurst, MacLean, and Taylor (1943) also found these intracellular structures in the throats of $65 \%$ of 224 apparently healthy students. Although in the present series there is a greater incidence in the cases of acute respiratory infection than in the others it is clear that in any individual 
case the presence of cytoplasmic inclusions in the pharyngeal epithelium cannot be regarded as evidence of an active virus infection.

Summary. Cold agglutinin tests were performed on 66 infants and children with acute bronchopulmonary infections and on 48 controls during a three-month period in 1950 . High or rising titres were encountered five times more often in the presence of pulmonary damage than in its absence, It is suggested that the phenomenon is a non-specific reaction to pulmonary injury.

Swabs of pharyngeal epithelium were stained for cytoplasmic inclusion bodies in 59 patients with acute respiratory infections and in 27 controls. They were found in three-quarters of the patients examined, and in cases of acute chest disease no relationship could be established between their presence and any other clinical or pathological findings.

It is concluded that neither of these techniques yields reliable evidence of the activity of viruses in acute pulmonary infections.

\section{Conclusions}

It would appear from the above considerations that the diagnosis of 'virus' pneumonia in infants and children does not rest on any secure basis. The term should probably be avoided except in cases such as influenza and psittacosis where definite proof of the activity of a known virus can be established. Claims for the effectiveness of chemotherapeutic agents in a condition of such doubtful authenticity should accordingly be treated with reserve.

I am indebted to Professor R. W. B. Ellis, Dr. D. N. Nicholson, and Dr. J. L. Henderson, of the Royal Edinburgh Hospital for Sick Children, for permission to consult the records of their cases; to Dr. D. V. Hubble and Dr. E. J. S. Woolley for allowing me to investigate the cases in their charge in Derby; to Dr. G. R. Osborn for the provision of pathological facilities; to the laboratory staffs of the Derby hospitals for assistance; and to Mr. J. Fayers for the microphotograph. I wish to thank Professor Ellis for advice on the presentation of this material.

\section{REFERENCES}

Adams, J. M. (1948). Amer. J. Dis. Child., 75, 544. Green, R. G., Evans, C. A., and Beach, N. (1942). J. Pediat., 20, 405.

Pennoyer, M. M., and Whiting, A. M. (1946). Amer. J. Dis. Child., 71, 162.

Broadhurst, J., MacLean, E., and Taylor, I. (1943). J. infect. Dis., 73, 191.

Dingle, J. H. (1947). Advanc. Pediat., 2, 194.

Gedgoud, J. L. (1943). Neb. St. med. J., 28, 51.

Heffron, R. (1939). 'Pneumonia.' New York.

Israel, H. L., Mitterling, R. C., and Flippin, H. F. (1948). New Engl. J. Med., 238, 205.

Kinsman, J. M., Daniels, W. B., Cohen, S., McCracken, J. P., D'Alonzo, C. A., Martin, S. P., and Kirby, M. M. (1945). J. Amer. med. Ass., 128, 1219.

McDermott, W. (1946). In 'Nelson Loose-Leaf Living Medicine,'Vol. 1, Ch. 6, pp. 141-257. New York.

McNeil, C. (1939). Edinb. med. J., 46, 153.

McNeil, C., Macgregor, A. R., and Alexander, W. A. (1929). Archives of Disease in Childhood, 4, 12.

Rabe, E. F. (1948). Pediatrics, 2, 255.

Reimann, H. A. (1947). Medicine, Baltimore, 26, 167.

Savonen, K. (1950). Acta med. scand. Suppl., 239, 133.

Young, L. E. (1946). Amer. J. med. Sci., 211, 23. 